Ann. Biol. anim. Bioch. Biophys., 1979, 19 (3 A), 661-688.

\title{
L'organe pinéal du Brochet (Esox lucius, L.) II. Etude en microscopie électronique de la différenciation et de la rudimentation partielle des photorécepteurs; conséquences possibles sur l'élaboration des messages photosensoriels
}

\author{
par J. FALCON *
}

Laboratoire de Zoologie et Biologie cellulaire et

Laboratoire associé au CNRS $n^{\circ} 290$,

40, Avenue du Recteur Pineau, 86022 Poitiers Cedex, France.

Summary. The pineal organ of the pike, Esox lucius L. II. - An electron microscopic study of photoreceptor cell differentiation and regression and variations of the photoreceptive potential in different pineal regions.

Photoreceptor cells $(P)$ of the pike pineal organ were examined by electron microscopy. They showed the usual structural pattern (outer segment, inner segment, cell body, basal process(es)) of the pineal cone-like P-cells of lower vertebrates. P-cell plurality was established. Considering the different regions of the pike pineal, at least two segments of P-cells varied greatly. In the distal part of the pineal end-vesicle and the pineal stalk, these cells often had a regular outer segment (a dome-like stack of 20 to 30 curved disks) and basal processes; the latter radiated into the neuropile areas, showing characteristic synaptic ribbon contacts with the dendritic processes of sensory neurons. On the contrary, P-cells located mainly in the middle pineal showed remarkable structural changes : disarranged internal organization and a degeneration of the outer segments, some of which were bulbous. Moreover, the typical synaptic ribbon contacts were missing. However, vesicle-crowned ribbons were present in the basal processes, some of which touched the basal lamina. These regressed P-cells had a number of common features with the rudimentary photoreceptor cells of Sauropsida. Considering the ultrastructural characteristics of P-cells, it was proposed that the photosensory function of the pike pineal was mainly developed in the proximal and distal pineal regions. On the contrary, in the middle folded pineal epithelium, much (or all ?) of the photoreceptive potential was lost. Using ultracytochemical methods, a large number of glycogen particles were visualized in P-cells. Considering the specificity of the techniques used, the presence of proteinic and/or glycoproteinic inclusions in several pineal cell types was discussed. No definitive evidence of secretion was deduced, but scarce dense-cored vesicles were sometimes observed in well differentiated and regressed P-cells.

* Present address : Max-Planck-Institut für Physiologische und Klinische Forschung. W. G. Kerckhoff-Institut, Parkstrasse 1, 6350 Bad-Nauheim, BRD. 


\section{Introduction.}

Collin $(1969,1971)$ a montré qu'au cours de la phylogenèse, les cellules photoréceptrices (ou photorécepteurs $=P$ ) de l'organe pinéal subissent une rudimentation. Bien représentées chez les Anamniotes adultes, elles cèdent peu à peu la place aux photorécepteurs rudimentaires (PR), surtout chez les Chéloniens, Lacertiliens et Oiseaux, et aux pinéalocyłes $(\mathrm{Pi})$ principalement chez les Ophidiens ef les Mammifères. Après avoir mis en évidence les homologies entre ces types cellulaires, l'auteur propose le concept, actuellement admis, d'une « lignée des cellules sensorielles » (Collin, 1969, 1971) ou «lignée des cellules réceptrices 》 (Collin, 1979). Ce concept a reçu de nouveaux fondements grâce à Clabough (1973, chez Raftus et Mesocricetus), à Zimmerman et Tso (1975, chez Rattus) et à Meiniel (1976, chez Lacerta), qui ont pu saisir les phases de la rudimentation au cours de l'ontogenèse. Chez les Amniotes, un organe pinéal peut montrer 2 à 3 des types cellulaires précédents, d'où la notion de « pluralité des cellules de la lignée sensorielle » (Collin, 1969, 1971).

La signification de la photosensibilité directe de l'organe pinéal des Anamniotes et de certains Reptiles, demeure inconnue ; chez les Ophidiens et les Mammifères, et de façon vraisemblable chez les Oiseaux, elle a disparu. « La fonction fondamentale et constante de l'organe pinéal des Vertébrés, photodépendant, est caractérisée par l'élaboration de messages. La rudimentation des photorécepteurs entraîne la disparition du message nerveux, mais on ignore à quel niveau de la lignée des Vertébrés et selon quelles modalités apparaît l'élaboration de messages de type neurohormonal » (Collin, 1977). En bref, il s'agit de savoir si, chez les Anamniotes, les messages neurohormonaux sont élaborés dans les photorécepteurs typiques et/ou dans les cellules "photoréceptrices » à caractères rudimentaires.

L'étude préliminaire, réalisée par Owman et Rüdeberg (1970), permet de penser que l'organe pinéal du Brochet (Esox lucius, L.) - comme celui de certains autres Téléostéens - synthétise et stocke des composés de nature indolique (réf. in Falcon, 1979). Chez certains Sauropsidés, les messages neuro-hormonaux sont élaborés dans les PR (réf. in Collin, 1977 ; Collin et al., 1977 ; Juillard ef al., 1977) ; cette propriété est plus admise qu'éłablie au niveau des $\mathrm{Pi}$, chez les Mammifères (Collin, 1977).

Avant d'entreprendre l'étude des sites cellulaires du métabolisme indolique, il est donc indispensable de s'assurer si, contrairement aux conclusions de Owman et Rüdeberg (1970), certaines cellules de type photorécepteur (CTP) de l'organe pinéal du Brochet présentent des caractères de rudimentation (comme c'est le cas chez les Amniotes). En d'autres termes, existe-t-il déjà chez les Anamniotes, comme chez certains Sauropsidés, une pluralité des cellules de la lignée sensorielle, susceptible de justifier une pluralité des messages?

Répondre à cette question nécessite une éfude préliminaire ultrastructurale et cytochimique des CTP dans les régions précédemment définies (distale, moyenne, proximale : Falcon, 1979).

\section{Matériel et méthodes.}

1. Matériel biologique (voir Falcon, 1979). - Les Brochets ont été sacrifiés en novembre, entre $11 \mathrm{~h}$ ef $13 \mathrm{~h}$. 
2. Techniques de microscopie électronique (voir Falcon, 1979).

3. Techniques de mise en évidence des strucłures de nature glucidique ef glycoprotéique en microscopie électronique.

a) Technique à l'acide périodique-thiocarbohydrazide (TCH)-protéinate d'argent (PA). Une épiphyse de Brochet est fixée au glutaraldéhyde à 2 p. 100, dans le tampon phosphate $(0,1 \mathrm{M} ; \mathrm{pH} 7,4)$ pendant $15 \mathrm{~min}$, puis rincée toutes les $2 \mathrm{~h}$ pendant $12 \mathrm{~h}$ dans le même tampon, déshydratée par les alcools ef incluse dans l'araldite.

Les coupes ultrafines, recueillies sur grilles en or sont ensuite traitées selon la technique mise au point par Thiéry (1967). Certaines coupes (témoins) ne sont pas traitées par l'acide périodique, d'autres par le $\mathrm{TCH}$.

b) Technique à l'acide phosphofungstique (PTA). Une épiphyse de Brochet est fixée comme précédemment (voir a) mais incluse dans le glycolméłacrylate (GMA). Les coupes ultrafines recueillies sur grilles en or, sont colorées $10 \mathrm{mn}$ par le PTA (en solution à 1 p. 100 dans l'acide chlorhydrique normal) selon Rambourg $(1967,1969)$ ef Rambourg et al., (1969).

\section{Résultats.}

1. Ultrastructure des cellules de type photorécepteur (= CTP) (fig. 1, 2).

Comme l'a montré l'étude cytologique préliminaire (Falcon, 1979), une CTP est construite sur le même plan que celui des cellules photoréceptrices des yeux latéraux. Les quatre parties fondamentales, distinguées lors de l'étude précédente, seront examinées dans le détail.

a) Segment externe.

- Segment externe de type régulier. Il est constitué par un empilement régulier de 20 à 30 disques ou saccules qui encapuchonnent en grande partie l'apex du segment interne sous-jacent (fig. 3,4 ), en forme de massue, faisant ou non saillie dans la lumière de l'organe (fig. 1, 2). Les disques, de 200 à 300 A d'épaisseur, sont reliés à la masse du segment interne par une structure ciliaire ou segment connectif qui présente en coupe transversale l'organisation caractéristique $9+0$ ( 9 doublets de microtubules périphériques +0 doublet central : fig. $1,4,5$ ). A la base, le segment connectif a l'aspect d'une étoile à 9 branches qui tend à s'élargir ef prendre une forme circulaire à l'approche des disques. Il est relié au centriole axial localisé à la partie distale du segment interne (voir 1. b) (fig. 1, 3, 10). La membrane des disques présente des rapports de continuité avec le plasmalemme. Chaque saccule est «ouvert» sur la lumière du côté opposé à la structure ciliaire (fig. 6) ; au niveau de cette dernière, les disques sont fermés (fig. 5). Il en résulte que l'intérieur d'un disque est en contacł avec la lumière de l'organe, tandis que l'espace entre 2 disques est en relation avec le hyaloplasme ciliaire.

Sur les coupes réalisées perpendiculairement au grand axe de la cellule, les disques présentent une disposition concentrique (fig. 7). Leur forme circulaire est probable, mais ne peut être démontrée avec certitude à cause des flexures (Collin, 1969 chez Lampetra planeri) plus ou moins nombreuses et prononcées (fig. 3, 4). Parfois 
certains disques, particulièrement «longs » (la «longueur » d'un disque correspond à la distance séparant le côté "ouvert» du côté «fermé ») quittent l'empilement régulier pour se joindre au segment exłerne d'une CTP voisine (fig. 3).

Les segments externes de type régulier sont essentiellement observés dans les régions distale et proximale.

- Segment exferne de type irrégulier. De nombreux segments externes ont perdu l'organisation régulière. Plusieurs types ont été caractérisés se distinguant par : - des variations plus ou moins prononcées dans l'épaisseur des disques et/ou de l'espace hyaloplasmique (fig. 2,8 ) ;

- une réduction considérable du nombre et/ou de la longueur des disques ;

- des dilatations de l'espace hyaloplasmique pouvant donner naissance à des formations tubulaires et vésiculaires après fragmentation ; tous les stades intermédiaires entre les formes régulières et uniquement tubulaires ef vésiculaires sont visibles (fig. 9, 10) ;

- une protubérance en « massue » de la structure ciliaire dans la lumière, montrant 4 à 5 disques et qui contient fréquemment du matériel vésiculaire (fig. 11,12 ).

FIG. 1. - Les différents types cellulaires de l'épithélium épiphysaire du Brochef (Esox lucius L.). Reconstitution à partir de l'étude en microscopie électronique.

1) Photorécepteur (photoreceptor cell) ; 1') Cellule de type photorécepteur à caractères rudimentaires (photoreceptive cell which evolves into regressed photoreceptor cells). 2) Cellule interstitielle de type épendymaire (supporting celi). 3) Neurone sensoriel (sensory neuron). 4) Cellule à inclusions indéterminées (cell with undetermined inclusions). 5) Cellule phagocytante - ou macrophage - dans la lumière (phagocytotic cell — or macrophage - in the pineal lumen).

at : terminaison axonique (axon terminal) ; $a x$ : axone (axon) ; bl : lamelle basale (basal lamina) ; $c_{1}$ : centriole axial (axial centriole) ; $c_{2}$ : centriole distal (distal centriole) ; ca : capillaire (capillary) ; $c b$ : corps cellulaire (cellular body) ; $c f:$ fibre de collagène (collagen fiber) ; ch : chromatine (chromatin) ; ci $(9+1)$ : cil (cilium) ; cis : citerne ergastoplasmique (cisterna of rough endoplasmic reticulum); cn : cou cellulaire (cellular neck); cs $(9+0)$ : segment connectif (connecting segment) ; de : desmosomes ; dcr : vésicule à cœur dense (dense-cored vesicle) ; dd : dendrite (dendritic process) ; dos : segment externe désorganisé (disintegrated outer segment) ; e : endothélium des capillaires (endothelial cell) ; el : mitochondries constituant l'ellipsoïde (mitochondria of the ellipsoid) ; er : erythrocyłe ; $f$ : fibroblaste ; $g$ : appareil de Golgi (Golgi complex) ; $g$ : glycogène (glycogen particles) ; icp : prolongement d'une cellule interstitielle (interstitial cell process) ; ios : segment externe irrégulier (irregular outer segment); is : segment interne (inner segment) ; ly : lysosome ; $m$ : mitochondrie (mitochondrion) ; $m f:$ microfilaments ; $m f:$ microtubules ; $m v$ : microvillosités (microvilli) ; $m w$ : structure membranaire concentrique (membranous whorl) ; $n$ : noyau (nucleus); ne : membrane nucléaire (nuclear envelope) ; nf : neurofilament; $n f$ : neurotubule ; nu : nucléole (nucleolus) ; pc : péricyte ; $p$ : lumière épiphysaire (pineal lumen) ; pp : pédicule de photorécepteur (photoreceptor cell process) ; $p r p$ : pédicule de photorécepteur rudimentaire (process of a rudimentary photoreceptor cell) ; ps : espace périvasculaire (perivascular space) ; py : polysome ; rb : corps résiduel (residual body) ; rer : ergastoplasme (rough endoplasmic reticulum); ros : segment externe régulier (regular outer segment) ; ser : reticulum agranulaire (smooth endoplasmic reticulum); sr : ruban synaptique (synaptic ribbon) ; sv : vesicule synaptique (synaptic vesicle) ; $t j$ : tight junction ; ui : inclusion de type indéterminé (undetermined inclusion) ; vcr : ruban circonscrit par des vésicules (vesicle-crowned ribbon); vf : vacuole contenant un matériel floculeux (vacuole containing flocculent material) ; za : zonula adherens. 


\section{PLANCHE ।}

\section{Ultrastructure des cellules de type photorécepteur}

FIG. 2. - Epithélium épiphysaire d'Esox lucius L. photorécepleur typique, dans la région proximale.

La partie apicale du segment interne (is), de même que le segment externe (os), ne font pas, ici, saillie dans la lumière épiphysaire. Au niveau du cou cellulaire ( $c n$ ), la membrane cytoplasmique différencie une zone de jonction ou zonula adherens $(z a)$. Les mitochondries $(m)$ sont nombreuses dans le segment interne où elles constituent l'ellipsoïde (el) dans les régions apicale ef proximale. L'appareil de Golgi $(g)$ occupe une position supranucléaire ; à proximité, on remarque des lysosomes $(l y)$. Le corps cellulaire $(c b)$ contient le noyau $(n)$. Le pédicule du photorécepteur ( $p p)$ n'atteint pas la lamelle basale $(b l)$; il présente souvent une accumulation de vésicules claires (cr). Au contact entre 2 pédicules de photorécepteur, les membranes cellulaires peuvent différencier plusieurs types de jonction : des fascia odherens (tête de flèche large) et des tight (?) ou gap (?) junctions (petite flèche). Noter également la présence de microtubules $(m t)$ et de faisceaux de microfilaments $(m f)$.

(IC : cellule interstitielle ; ps : espace péri-capillaire) $(\times 12000)$. 


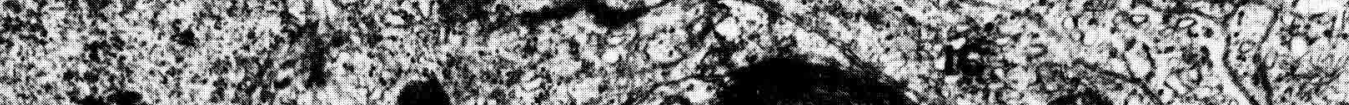

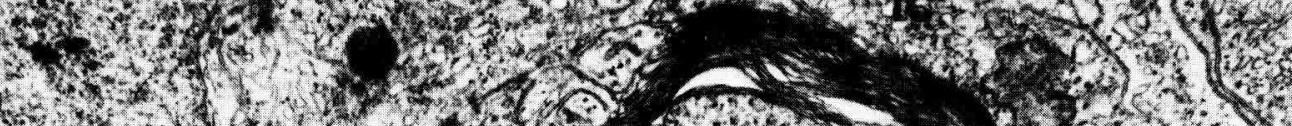

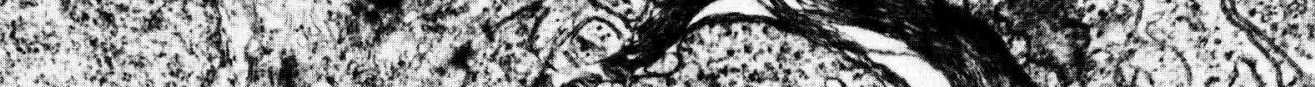

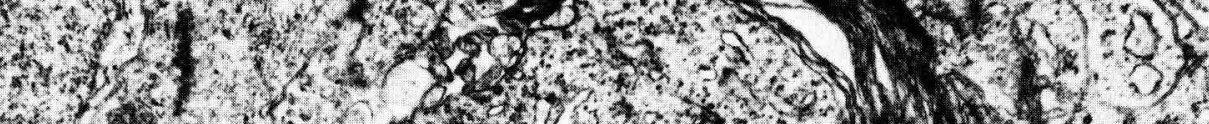



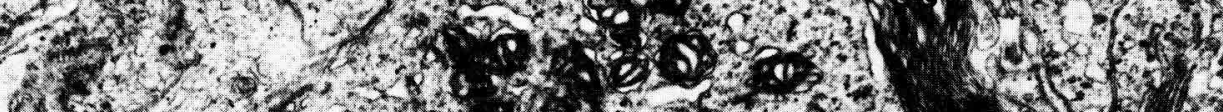



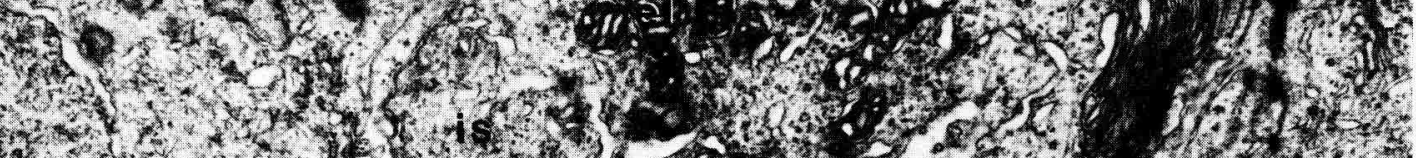

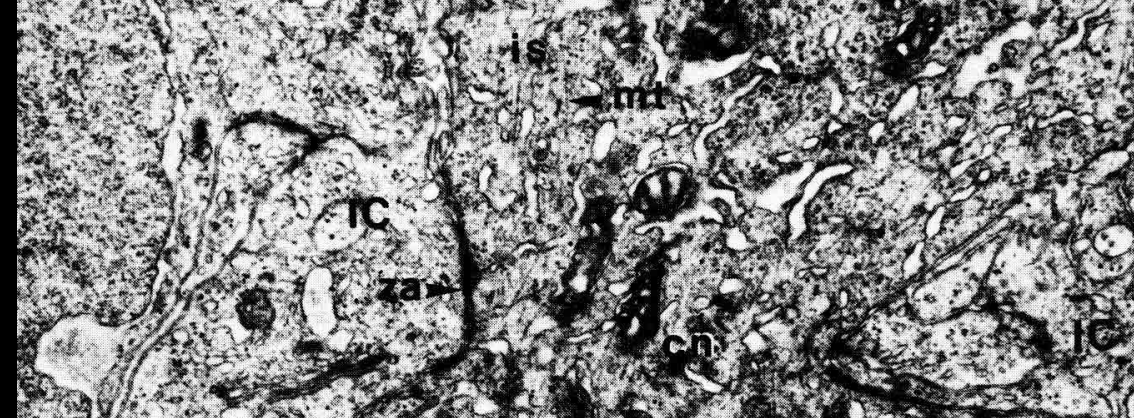

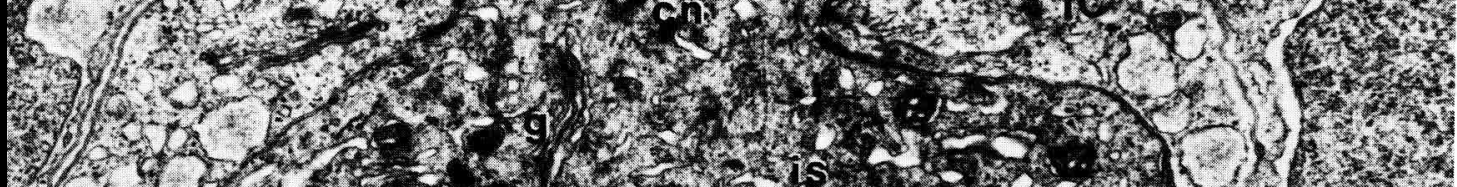



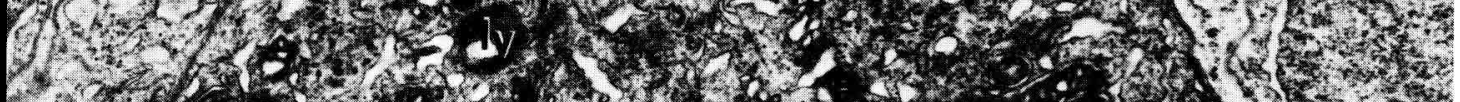



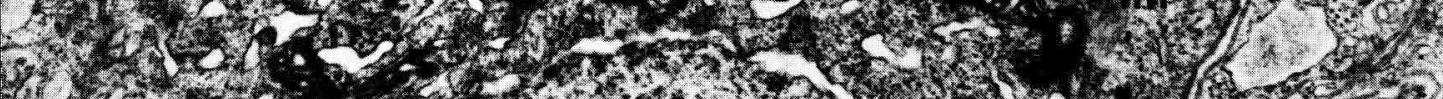





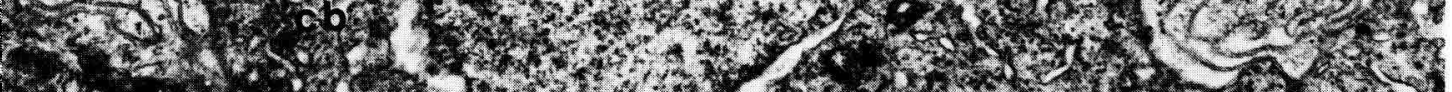

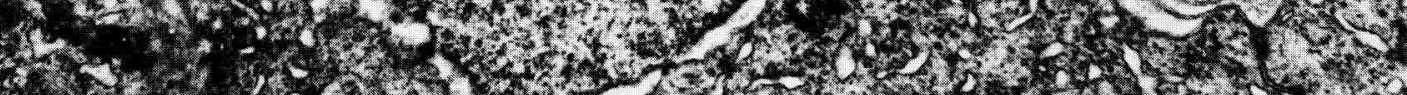

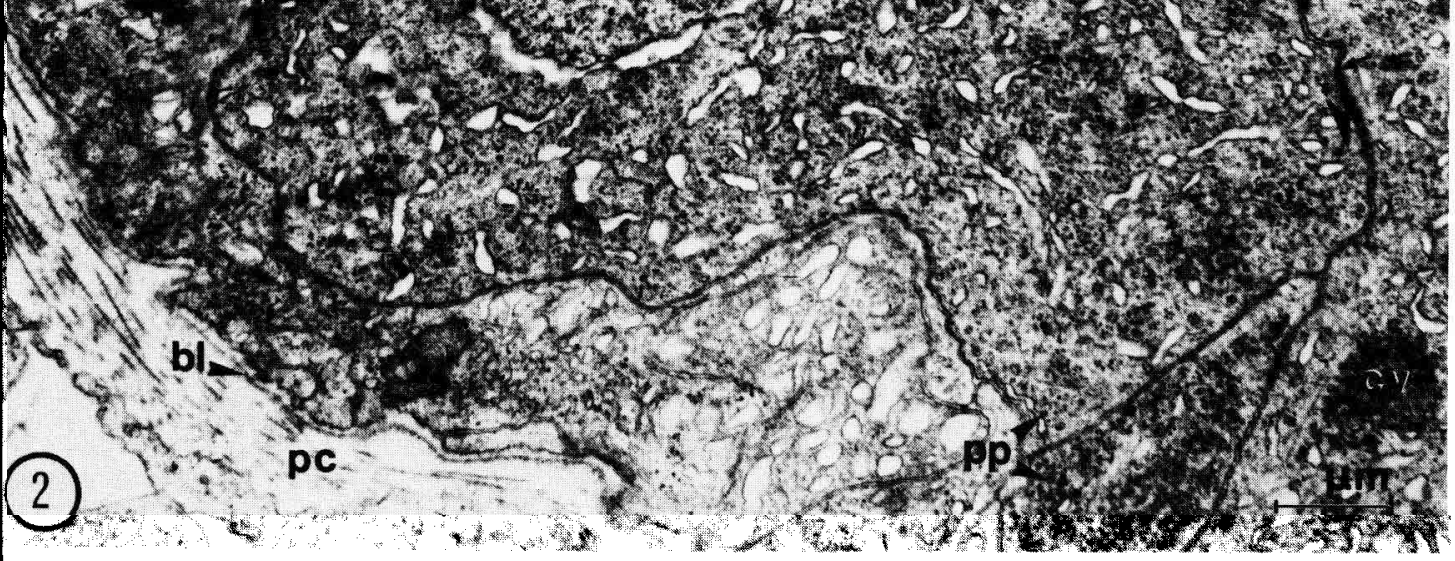




\section{PLANCHE II}

\section{Ultrastructure des cellules de type photorécépteur}

FIG. 3. - Segment exierne de type régulier (ros). Parfois certains disques quittent l'empilement régulier (flèches blanches) et vont se joindre aux disques du segment externe d'un photorécepteur voisin. (cs : segment connectif ; is : segment interne) ( $\times 16500)$.

FIG. 4. - Segment externe de type régulier. Les petites flèches blanches montrent les flexures des disques. Chaque disque (espace compris entre 2 grandes têtes de flèches blanches) est fermé (petiłe flèche noire) du côté du segment connectif ( $\times 20000)$.

FIG. 5. - Segment connectif, montrant 9 doublets de tubules périphériques (flèches), $(\times 60000)$.

FIG. 6. - Du côté opposé à la structure ciliaire, chaque disque (espace entre 2 têfes de flèches larges) est ouvert sur la lumière (tête de flèche étroite) $(\times 40000)$.

FIG. 7. - Segment externe de type régulier. Les disques présentent une disposition concentrique sur cette coupe réalisée perpendiculairement au grand axe de la cellule, (17 000).

FIG. 8. - Segment externe de fype irrégulier (ios). Remarquer les variations de l'espace hyaloplasmique ef de l'épaisseur des disques (is : segment interne) (× 14000).

FIG. 9 et 10. - Segments externes de type irrégulier.

Fig. 9. - Dilatation des disques (flèches), suivie de fragmentation entraînant la formation de tubules et vésicules $(\times 38500)$.

Fig. 10. - Le segment externe (ios) est constitué eșsentiellement de vésicules ef tubules. Le centrosome est localisé à la partie apicale du segment interne (is) ; il est composé d'un cenfriole distal $\left(c_{1}\right)$ et d'un centriole proximal $\left(c_{2}\right)(\times 19000)$. 
cou cellulaire, et parfois de lysosomes (fig. 1, 2). Comme dans le reste de la cellule, les particules de glycogène sont abondantes (voir paragraphe 3 ) et les ribosomes nombreux s'associent fréquemment en rosettes pour former des polysomes.

- Le cou cellulaire (fig. 1, 2). - La région du cou est traversée par de nombreux microtubules orientés parallèlement au grand axe cellulaire. Lorsque la constriction est peu marquée, s'observent des mitochondries, plus rarement un dictyosome. La membrane cytoplasmique différencie à la périphérie une ceinture de jonction (= zonula adherens).

- La région proximale. - Les mitochondries, comme dans la région apicale, sont souvent en nombre élevé et présentent les mêmes caractéristiques.

Le myoïde renferme les éléments responsables des synthèses et concentrations des composés protéiques et glycoprotéiques. L'appareil de Golgi occupe une position supra-nucléaire (fig. 1, 2) ; les dictyosomes sont composés de saccules parfois allongés ef dilatés (fig. 13). Aux abords immédiats, on observe des vésicules claires de 600 à $900 \AA$ de diamètre. Le réticulum lisse est constitué de vésicules et de saccules souvent interconnectés qui, dans certains cas, semblent entrer directement en relation avec l'appareil de Golgi (fig. 13). Le réticulum granulaire est composé de saccules dilatés. De telles dilatations, comme celles de l'enveloppe nucléaire, pourraient être d'origine artéfactuelle, liée au processus de fixation.

On observe également des microtubules ef quelques lysosomes (fig. 1, 2).

c) Le corps cellulaire (fig. 1, 2, 14).

II contient le noyau, généralement ovoïde. La chromatine est uniformément répartie à l'intérieur d'une enveloppe nucléaire perforée de nombreux pores. Le nucléole dense occupe une position excentrique.

Dans la zone périnucléaire, on observe quelques mitochondries, des microtubules et d'importants faisceaux de microfilaments (fig. 1, 2). L'ergastoplasme (voir remarques précédentes) est constitué de saccules « allongés 》 qui présentent une disposition concentrique autour du noyau. Entre les saccules, on remarque des inclusions de 850 à $1350 \AA$ de diamètre remplies d'un matériel floconneux, peu dense aux électrons (fig. 14). Parfois des vésicules claires de 350 à $500 \AA$ de diamètre forment des amas dans le périkaryon (fig. 14).

d) Le(s) pédicule(s) basal(aux).

Le corps cellulaire est en relation avec un ou plusieurs prolongements (ou pédicules basaux), éventuellement ramifiés et renflés à leur extrémifé, orientés vers la lamelle basale. Dans la majorité des cas, ils forment des groupes de terminaisons au niveau du tiers basal de l'épithélium épiphysaire (fig. 1, 2, 15). Dans cette région - zone des neuropiles - peuvent s'établir des contacts synaptiques avec les expansions dendritiques des neurones sensoriels pinéalofuges (voir Falcon, 1979 ef ultérieurement). Dans la région moyenne, d'autres pédicules, non renflés à leur extrémité, viennent prendre « appui » sur la lamelle basale (fig. 1, 16).

Le long d'un pédicule basal, on observe de nombreux microtubules, d'importants faisceaux de microfilaments et quelques mitochondries (fig. 15, 18). Le réticulum, 
peu représenté, esł généralement lisse. Les saccules, allongés, s'orientent parallèlement au grand axe du prolongement.

La présence de nombreuses vésicules claires constitue la caractéristique essentielle. Leur diamètre varie de 350 à $500 \AA$ pour la majorité. Elles forment des amas le long du pédicule et s'accumulent généralement dans la partie terminale, renflée (fig. 1, 2, 15) ; elles sont parfois rares.

Quelquefois, on observe parmi les vésicules claires, de rares vésicules à cœur dense de 600 à $1000 \AA$ de diamètre (fig. 15, 25). Elles sont également présentes dans les pédicules qui atteignent la lamelle basale (où les vésicules claires sont peu représentées). Certaines électronographies suggèrent que le contenu dense aux électrons de ces vésicules est libéré par exocytose dans l'espace périvasculaire (fig. 17).

e) Dégénérescence des cellules de type photorécepteur (fig. 19, 20).

Certaines CTP sont affectées par des modifications ultrastructurales importantes. Leur hyaloplasme particulièrement sombre permet de les identifier aisément. II s'agit de CTP en dégénérescence.

Le segment externe est le premier atteint par ce phénomène ; il devient de type irrégulier (vésiculaire et tubulaire). Les saccules golgiens, très dilatés, sont le siège d'une activité intense, vraisemblablement liée à l'élaboration d'hydrolases. En effet, à leur voisinage et dans toute la cellule, s'observent de nombreux lysosomes, particulièrement développés et des vacuoles digestives contenant le plus souvent des structures membranaires concentriques (fig. 19, 20). Progressivement, le réticulum se vacuolise (fig. 20), les mitochondries se gonflent, la matrice perd son contenu dense et les tubules régressent (fig. 19, 20).

Dans un dernier stade, le chondriome ainsi que la majorité des organites cyłoplasmiques sont digérés; la vacuolisation du réticulum s'est accentuée. Dans le cytoplasme, ne se rencontrent plus que d'importants faisceaux de microfilaments et des microłubules ; les particules de glycogène forment des amas importants. Les vésicules claires de 350 à $500 \AA$ de diamètre ont disparu.

2. Les différents types de jonctions cellulaires.

a) Connexions synaptiques.

Dans certaines zones des neuropiles, des contacts synaptiques de type ruban, s'établissent entre les pédicules des CTP et les dendrites des neurones sensoriels (NS).

Les rubans synaptiques (RS), accompagnés dans la majorité des cas par des vésicules claires (de 350 à $500 \AA$ de diamètre) ou vésicules synaptiques, sont localisés près de la membrane hyaloplasmique (ou membrane présynaptique) et disposés perpendiculairement ou obliquement à cette dernière (fig. 21, 23). Entre le RS et la membrane présynaptique, le hyaloplasme présente parfois une zone de densification arciforme (fig. 22, 23 ; voir aussi Falcon et Mocquard, 1979, fig. 25). Une densification post-synaptique du neuroplasme dendritique (localisée en face du RS), contiguë à la membrane, est plus rarement observée (fig. 22 ef in Falcon et Mocquard, 1979, fig. 25). La périphérie du RS et parfois une bandelette qui se superpose au plan sagittal, sont relativement denses aux électrons; la matrice, plus ou moins contrastée, est toujours plus sombre que le cytoplasme avoisinant. 


\section{PLANCHE III \\ Ultrastructure des cellules de type photorécepteur}

FIG. 11 et 12. - Segment externe de type irrégulier. La structure ciliaire forme, dans les 2 cas, une protubérance en massue (bos), d'où partent latéralement quelques rares disques, relativement « courts 》 (d).

Fig. 11. - La protubérance contient du matériel vésiculaire $(\times 25000)$.

Fig. 12. - ( $c_{1}$ : centriole distal ; $c_{22}$ : centriole proximal ; is : segment interne; $m$ : mitochondrie) $(\times 12000)$.

FIG. 13. - Appareil de Golgi (g). Les saccules sont dilatés. A proximité, on observe des vésicules claires ( $g l$ : particules de glycogène ; py : polysomes) $(\times 35000)$.

FIG. 14. - Zone périnucléaire. Le réticulum endoplasmique granulaire (rer) forme des travées disposées concentriquement autour du noyau $(n)$. Noter également une accumulation de vésicules claires $(c v)$ ( $v f$ : vésicules contenant du matériel floconneux) ( $\times 44000)$.

FIG. 15. - Zone des neuropiles. Les pédicules de photorécepteurs $(p p)$ forment des groupes de terminaisons au niveau du tiers basal de l'épithélium épiphysaire. Ici, les vésicules claires sont peu nombreuses. La flèche indique la présence d'une vésicule à cœur dense ( $m$ : mitochondrie ; $m t$ : microtubule) $(\times 12000)$.

FIG. 16. - Pédicule de photorécepteur à caractères rudimentaires (prp) dans l'épiphyse moyenne. II prend appui sur la lamelle basale (bl). L'endothélium des capillaires (ca) montre ici de nombreux pores diaphragmés (flèches) et une jonction entre deux cellules endothéliales (cercle) ( $\times 14000)$. 


\section{PLANCHE IV \\ Ultrasiructure des cellules de type photorécepteur. Confacts synoptiques}

FIG. 17. - 3 vésicules à cœur dense (dcv) sont observées dans un pédicule de photorécepteur à caractères rudimentaires, qui prend appui sur la lamelle basale $(b l)$. Une libération du contenu dense des grains par exocytose (grande têfe de flèche) dans l'espace périvasculaire (ps) est suggérée $(\times 37500)$.

FIG. 18. - Important faisceau de microfilaments $(m f)$ et microfubules $(m t)$ dans un pédicule de cellule de type photorécepteur ( $\times 16500)$.

FIG. 19 et 20. - Cellule de type photorécepteur en dégénérescence.

Fig. 19. - Les saccules des dictyosomes $(g)$ sont particulièrement gonflés. Au voisinage, on remarque la présence de lysosomes $(l y)$. La matrice des mitochondries $(m) n$ 'est plus dense aux électrons, les crêtes régressent ( $\times 17000$ ).

Fig. 20. - Le réticulum est vacuolisé ( $v r)$; la cellule contient des structures membranaires concentriques $(m w)$ en digestion. (IC : cellule interstitielle ; $n$ : noyau; nu : nucléole) $(\times 8000)$.

FIG. 21, 22 et 23. - Contacts synaptiques de type ruban (sr) entre pédicules de photorécepteur ( $p p$ ) et expansions dendritiques ( $d d$ ) de neurones sensoriels (Falcon et Mocquard, 1979) qui pénètrent plus ou moins dans le pédicule. Des densifications pré et post-synaptiques sont parfois observées (petites flèches, voir également in Falcon et Mocquard, 1979, fig. 25).

Fig. 21 ( $\times 66000$ ).

Fig. $22(x .26000)$.

Fig. $23(\times 24000)$. 




(17) bi ps $\mathbf{l n m}^{1}$ (18)

$20.01,4 . \mu m$

- -3 in

(8)

6.

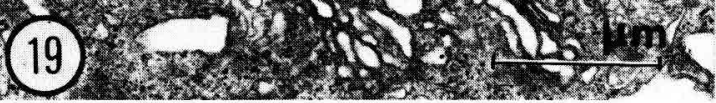

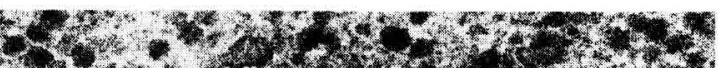

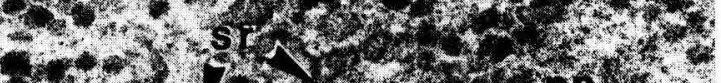

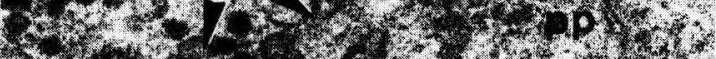

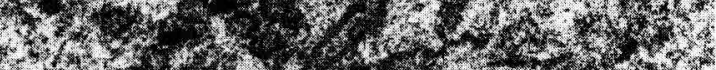

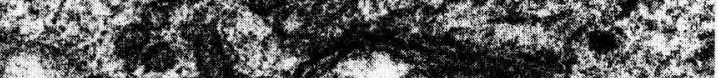



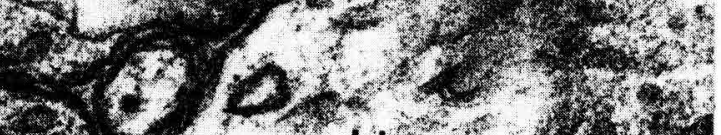

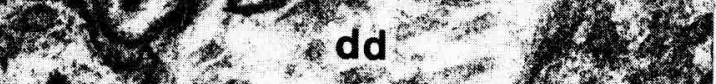

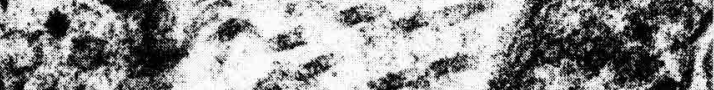

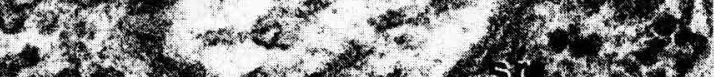

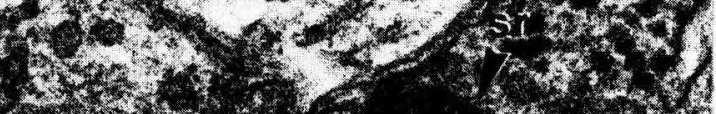

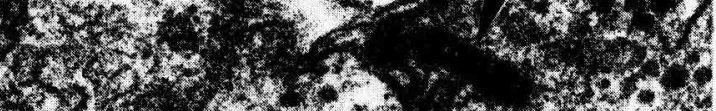
(21) $2 d^{2}, 2,540$ (20) (20)

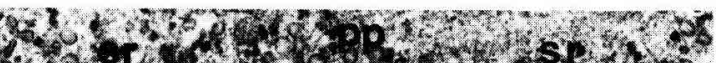
10.2 (22)

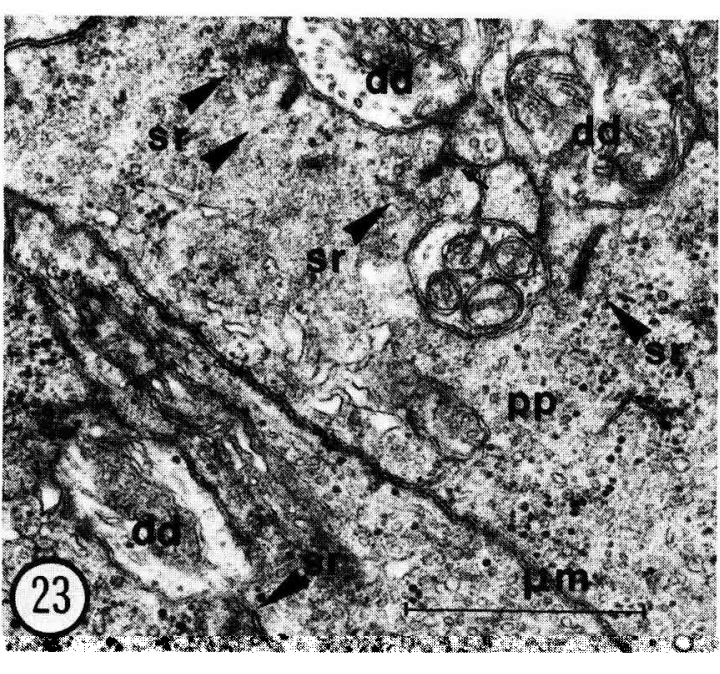

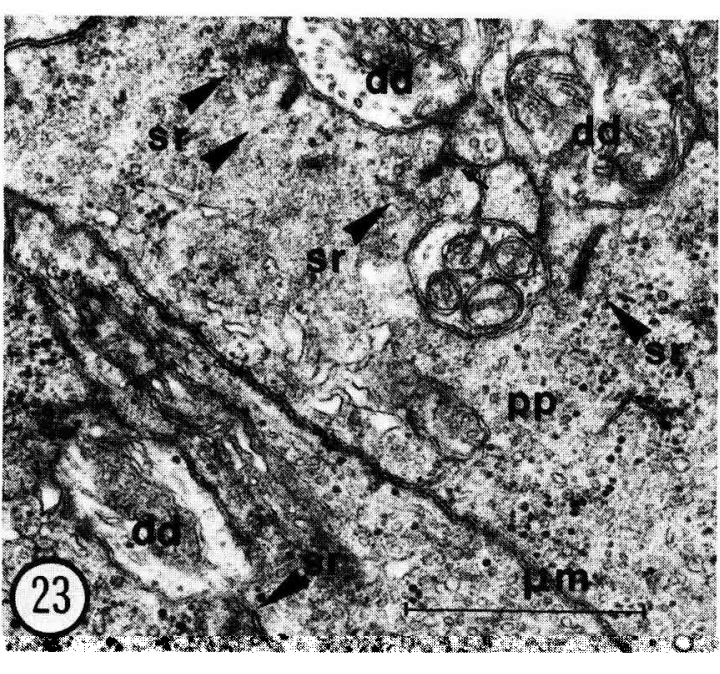

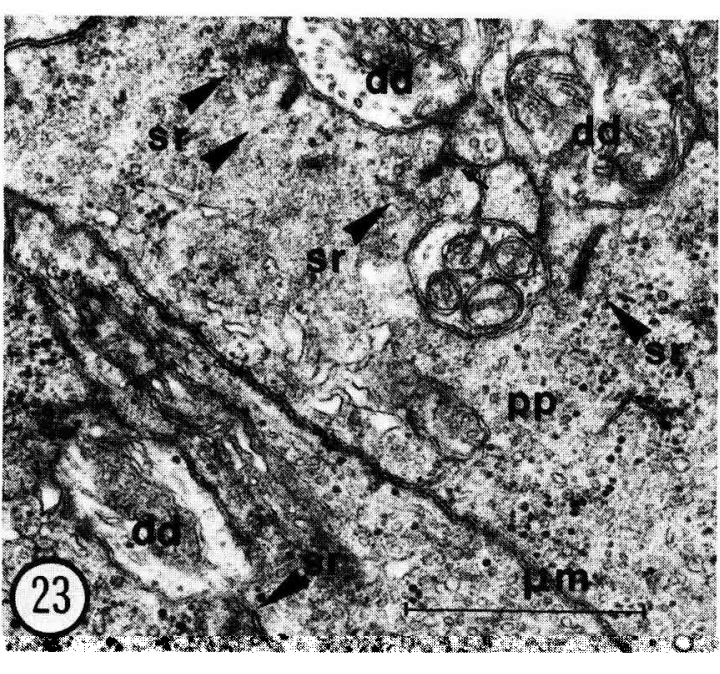

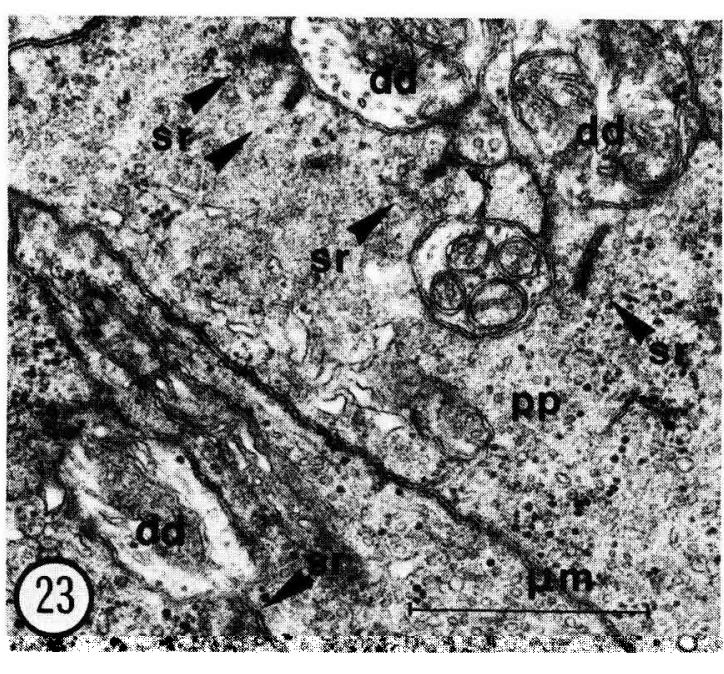

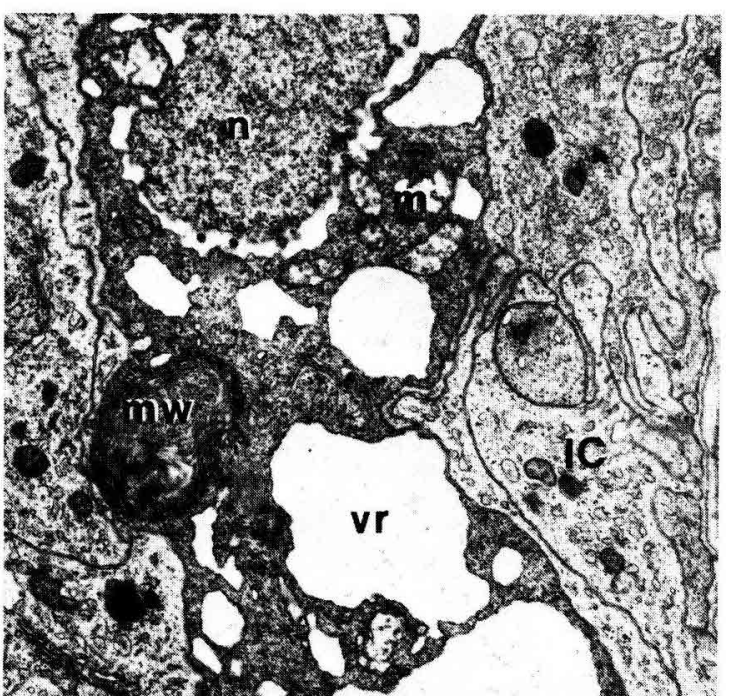




\section{PLANCHE V}

Ultrastructure des cellules de type photorécepteur ef contacts cellulaires

FIG. 24 à 28. - Rubans circonscrits par des vésicules (ver).

Fig. 24. - vcr libres dans le pédicule d'un photorécepteur à caractères rudimentaires (prp) ( $\times 37000)$.

Fig. 25. - vcr adjacent à la membrane cellulaire d'autres pédicules de photorécepteurs à caractères rudimentaires ( $p r p)$, ( $c v$ : vésicule claire ; dcv : vésicule à cœur dense), ( $\times 38500)$.

Fig. 26. - vcr adjacent à la membrane cytoplasmique, face à une cellule interstitielle (IC) (n : noyau) $(\times 38000)$.

Fig. 27. - vcr localisé face à 2 pédicules de photorécepteurs à caractères rudimentaires ( $p r p$ ). Noter la densification hyaloplasmique arciforme (flèche), ( $\times 44000)$.

Fig. 28. -2 ver face à face $(\times 60000)$.

FIG. 29. - Fascia adherens entre 2 cellules de type photorécepteur $(P)(\times 17000)$.

FIG. 30. - Macula adherens ou desmosome, entre 2 cellules interstitielles (IC). Les microfilaments (mf) convergent vers la zone de jonction $(\times 34000)$.

FIG. 31. - Macula occludens (ou gap junction ?) entre 2 cellules de type photorécepteur ( $\times 64000)$. 


\section{PLANCHE V}

Ultracytochimie des glucides.

FIG. 32 à 37. - Technique de Thiéry.

Fig. 32. - Coupe témoin, $72 \mathrm{~h}$ d'incubation. Aucune réaction n'est enregistrée ( $n$ : noyau ; $P$ : cellule de type pholorécepteur) ( $\times 20000$ ).

Fig. 33. - Coupe traitée $40 \mathrm{mn}$ : contrairement aux cellules interstitielles (IC) où seuls quelques précipités sont visibles, les cellules de type photorécepteur $(P)$ sont particulièrement riches en glycogène ( $X 28500)$.

Fig. 34. - A fort grossissement, on remarque que les particules $\beta$ de glycogène sont associées en rosettes pour former des particules (flèches) $(\times 82500)$.

Figs. 35 et 36 . - Coupes traitées $24 \mathrm{~h}$ : dans les cellules interstitielles $(I C)$, ou dans les cellules à inclusions indéterminées? (voir texte), des inclusions présentent des mucopolysaccharides au niveau de lisérés membranaires simples ou doubles (Fig. $35: \times 45000$ ) et de réseaux périphériques (Fig. $36: \times 67500$ ).

Fig. 37. - Coupe traitée $72 \mathrm{~h}$ : aucun marquage supplémentaire n'est observé par rapport aux 2 temps précédents; ici, un pédicule de photorécepteur rudimentaire ( $p r p)$, riche en glycogène, prend appui sur la lamelle basale (IC: cellule interstitielle; ps : espace périvasculaire) $(\times 60000)$.

FIG. 38 à 41. - Technique de Rambourg.

Fig. 38. - Epithélium basal : un marquage intense est observé au niveau de la lamelle basale $(b l)$ et des fibres de collagène ( $c f$ ) dans l'espace périvasculaire ( $p s)$. Les espaces intercellulaires sont moins bien marqués (flèches) $(\times 12000$ ).

Fig. 39. - Pédicule d'une cellule de type photorécepteur $(p p)$ : noter le marquage de la membrane (têtes de flèches) des vésicules claires de 350 à $600 \mathrm{~A}$ de diamètre $(\times 41000)$.

Fig. 40. - Marquage dense et hétérogène du contenu d'inclusions (grandes têtes de flèches) dans un type cellulaire non encore identifié. Noter le marquage par endroits, des espaces intercellulaires (petites têtes de flèches) ( $\times 36500$ ).

Fig. 41. - Témoin : aucun produit de réaction n'est observé. (IC : cellule interstitielle ; $P$ : photorécepteur ; $n$ : noyau) $(\times 12000)$. 
n.





(33)

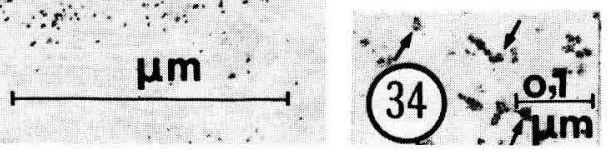

(35) $\frac{0,1}{\mu \mathrm{m}}$ (36) $\frac{0,1}{\mu \mathrm{m}}$ (37) ps $\frac{0,1}{\mu \mathrm{m}}$ $-2 \mathrm{c}-2$ pp $\mathrm{C}-\mathrm{s}=\mathrm{2}$

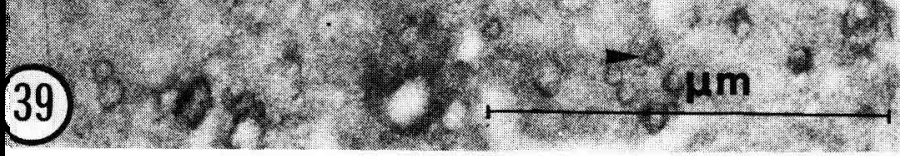
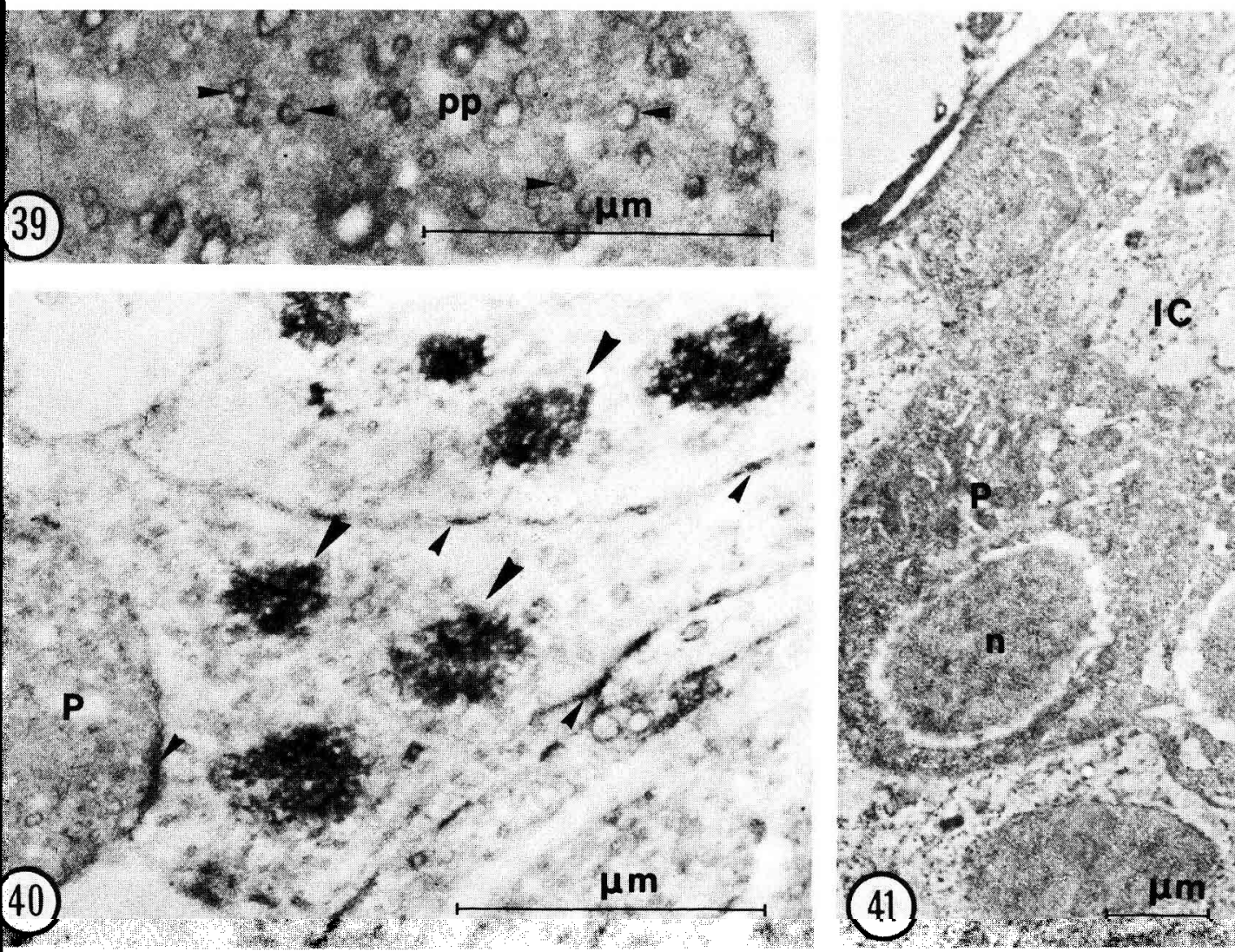

Dxt $=$ IC

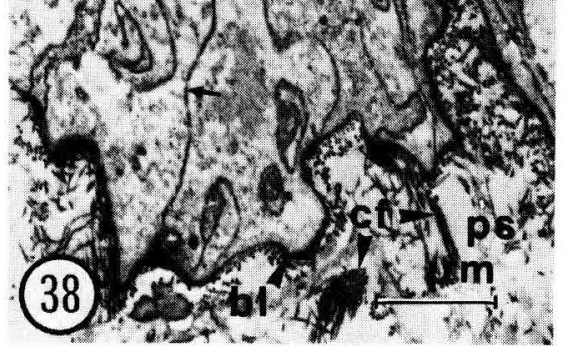

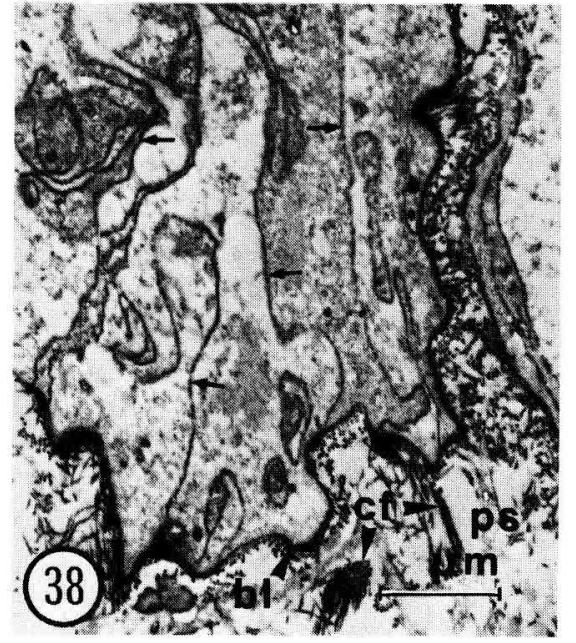


$5, x^{2}$ (c)



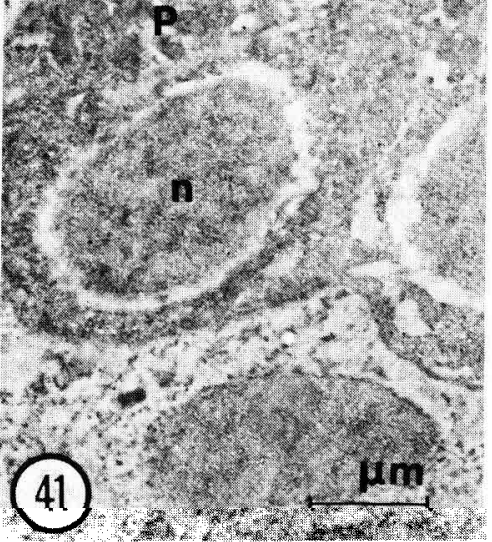


Les contacts synaptiques, essentiellement observés dans l'épithélium distal mais surtout proximal, peuvent s'établir de différentes façons (fig. 21, 22, 23) :

- un pédicule de CTP présente plusieurs RS localisés face à une (ou plusieurs) expansion(s) dendritique(s) (parfois un même RS peut être localisé en face de 2 dendrites : formation de diades) ;

- plusieurs pédicules de CTP peuvent établir des contacts avec une seule expansion dendritique.

Les RS n'ont jamais été localisés ailleurs que dans les pédicules des CTP. De plus, nous n'avons jamais observé de contacts synaptiques avec un corps cellulaire de neurone sensoriel (NS).

Dans certains cas, les expansions dendritiques pénètrent dans le pédicule basal (fig. 1, 23).

NOTA :

Dans les CTP, on observe d'autres formations présentant les mêmes caractéristiques ultrastructurales que les RS, mais qui ne peuvent être considérées comme tels. Ce sont les « rubans circonscrits par des vésicules " (= RCV) décrits par Collin (1969) chez le Vanneau.

Contrairement aux RS, les RCV ne sont pas toujours localisés près de la membrane hyaloplasmique du pédicule (fig. 24). Ils sont parfois observés dans le corps cellulaire. Dans la majorité des cas, ils sont adjacents à la membrane hyaloplasmique, mais sont localisés soit en face du corps cellulaire ou de pédicules d'autres CTP (fig. 25), soit plus rarement en face d'une cellule interstitielle (fig. 26). Entre l'extrémité des RCV et la membrane plasmique, on observe parfois une zone de densification arciforme (fig. 27, 28).

Un pédicule de CTP peut présenter un ou plusieurs RCV localisés face à un ou plusieurs tutres pédicules de CTP (fig. 25). Un RCV peut être situé en face de 2 pédicules (fig. 25, 27), ou face à un autre RCV d'une CTP voisine (fig. 28).

b) Contacts intercellulaires. - Plusieurs types ont été caractérisés :

- Les zonula adherens déjà signalées antérieurement ( $\$ 1 . b)$;

- Les fascia adherens (fig. 29) : entre cellules de type photorécepteur ; entre une cellule de type photorécepteur et une cellule interstitielle ; entre deux cellules interstitielles. Parfois quelques microtubules se rencontrent à proximité.

- Les macula adherens (ou desmosomes) (fig. 30), entre cellules interstitielles vers lesquelles convergent des structures filamenteuses (essentiellement des microfilaments).

- Les macula occludens ou «tight junctions » (fig. 31) entre CTP.

3. Ultracyfochimie des réserves énergétiques (glycogène) et des glycoprotéines.

a) Résultats apportés par la technique de Thiéry.

Après traitement, l'épithélium épiphysaire est le siège de réactions spécifiques, non perçues sur les coupes témoins (fig. 32) ; elles indiquent la présence de composés de nature glucidique. Les réactions dépendent du temps d'action du TCH (Thiéry, 1967) :

- Après $40 \mathrm{mn}$. - On observe, dans le cytoplasme des CTP, une accumulation importante de particules $\beta$ de glycogène, fréquemment associées en rosettes ef alors dénommées particules $\alpha$ (fig. 33, 34). Dans les cellules interstitielles de type épendymaire, le glycogène est beaucoup moins abondant. 
- Après 24 h. - La réaction avec le glycogène est très intense. Des inclusions de forme circulaire ou ovoïde (diamètre : 400 à $2000 \AA$; parfois beaucoup plus) sont marquées à la périphérie, soit par un liseré simple ou double de particules, soit par un réseau, laissant toujours apparaître une zone centrale non réactive (fig. 35, 36). Le marquage indique la présence de composés mucopolysaccharidiques. Ces inclusions, rares, ne sont jamais observées dans les CTP.

- Après 72 h. - Aucun marquage supplémentaire (significatif de la présence de glycoprotéines) n'a pu être enregistré par rapport aux 2 temps précédents (fig. 37).

b) Résultats apportés par la technique de Rambourg.

Cette technique permet de colorer la lamelle basale et les fibres de collagène dans l'espace périvasculaire (fig. 38) et, à un degré moindre, les membranes cyłoplasmiques (fig. 38, 39, 40). A fort grossissement, on remarque également un marquage des corps multivésiculaires et de la membrane des vésicules claires (de 350 à $600 \AA$ de diamètre) dans les CTP (fig. 39).

Dans un type cellulaire indéterminé (cellule interstitielle ?) des inclusions de forme circulaire à ovoïde présentent un contenu dense et hétérogène (fig. 40).

Sur les coupes témoins, aucun marquage n'est enregistré (fig. 41).

\section{Discussion.}

De l'étude ultrastructurale, il ressorf que 2 catégories de photorécepteurs sont présentes dans l'organe pinéal du Brochet : les photorécepteurs typiques et les photorécepteurs à caractères rudimentaires.

\section{Les photorécepteurs typiques.}

Ils présentent de nombreuses analogies avec ceux de la rétine des yeux latéraux, plus particulièrement avec les cônes : (a) segmentation de la cellule ; (b) polarité ef distribution stricte des organites cellulaires; (c) empilement régulier des disques - largement ouverts sur la lumière - dont la membrane est en continuité avec le plasmalemme ciliaire; (d) présence de plusieurs RS dans un même pédicule, accompagnés de différenciations particulières (vésicules synaptiques, densifications pré- et post-synaptiques) impliquées vraisemblablement dans la neurotransmission (voir discussion in Collin, 1969) ; les RS sont adjacents aux expansions dendritiques (des NS) qui pénètrent dans le pédicule basal sans véritablement s'invaginer comme dans le cas des bâtonnets rétiniens où en principe un seul RS est présent à la base du pédicule.

Les photorécepteurs typiques de l'organe pinéal du Brochet ont une ultrastructure très voisine de celle des photorécepteurs, décriłe chez les Cyclostomes (Collin, 1969), les autres Poissons (réf. in Falcon, 1979), les Batraciens et les Reptiles (réf. in Collin, 1979).

A chaque segment de la cellule correspond très vraisemblablement une spécialisation fonctionnelle : (a) dans les $P$ de la rétine, les membranes des disques du segment externe contiennent un photopigment impliqué dans la transduction du stimulus 
photique. Chez la plupart des Téléostéens, comme chez le Brochef, le nombre de disques par segment externe est relativement peu élevé ; mais l'adaptation à la transduction est liée plus à la surface membranaire totale exposée à la lumière qu'au nombre de disques (chez Esox le «diamètre » et le nombre des saccules suggèrent une surface moyennement importante). (b) Comme dans les $P$ de la rétine, l'ellipsoïde du segment interne fournit, vraisemblablement, l'énergie nécessaire aux différents métabolismes. (c) Dans le myoïde sont synthétisés protéines et glucides distribués dans toute la cellule. (d) Comme dans les cônes et bâtonnets de la rétine, le segment interne est très probablement impliqué dans la transmission de l'excitation, recueillie par le segment externe. (e) Le pédicule basal assure cette transmission aux NS pinéalofuges.

Cependant, la nature du photopigment des disques des cellules sensorielles de l'organe pinéal et celle du neurotransmetteur (présumé être localisé dans les vésicules synaptiques) de tous les photorécepteurs diencéphaliques sont à préciser ou à découvrir.

Les photorécepteurs typiques semblent plus particulièrement localisés dans les régions distale et surtout proximale de l'épithélium épiphysaire où les segments externes réguliers ef les pédicules synaptiques sont nombreux. II ressort de notre étude, effectuée dans chacune des régions, que l'organe pinéal du Brocheł semble être le premier à montrer une répartition héłérogène des $\mathrm{P}$ chez les Anamniotes.

\section{Cellules de type photorécepteur à caractères rudimentaires.}

Si toutes les CTP présentent la même organisation générale, nombre d'entre elles montrent une régression des structures polaires responsables de la transduction ef de la neurotransmission.

a) Régression du segment externe. - Les segments externes de type irrégulier sonf nombreux dans la région moyenne de l'épiphyse. lls ont également éfé observés chez d'autres Téléostéens (réf. in Falcon, 1979). Leur nombre et leur répartition pourraient varier d'une espèce à l'autre, d'un individu à l'autre. Différentes interprétations ont été proposées :

- Les variations de l'espace hyaloplasmique et/ou de l'épaisseur des disques, ainsi que les vésicules et tubules, pourraient résulter d'artéfacts dûs à la fixation (Oksche et Kirschstein, 1967 ; Rüdeberg, 1968, 1970 ; Takahashi et Kasuga, 1971). Mais cette hypothèse n'explique pas la présence d'expansions bulbeuses (présentant ou non quelques rares disques).

- Les structures irrégulières correspondraient à des disques pas ou peu fonctionnels entrant en phase de dégénérescence précédant l'éventuel renouvellement in toto du segment externe (Rüdeberg, 1970 ; Herwig, 1976). Mais ce processus de dégénérescence est totalement différent de celui du renouvellement des disques décrit par Young (1977) dans les cônes de la rétine de Sceloporus, où : (1) seuls quelques disques de la partie distale du segment externe se détachent uniquement pendant la période nocturne ; (2) des formations de vésicules et tubules ne sont pas observées ; (3) les disques sont immédiatement phagocytés par les cellules de l'épithélium pigmentaire. - Les disques dégénèrent graduellement au cours de la vie de l'individu selon un 
programme génétiquement déterminé, qui peut être influencé par l'action de la lumière. Nos observations chez Esox, avec celles d'autres auteurs chez certains Téléostéens, sonf en faveur d'une telle hypothèse : (1) Hafeez et Ford (1967) chez Oncorhyncus, Takahashi (1969) chez Carassius, Omura et Oguri (1971) chez Plecoglossus ef Poecilia, ef Herwig (1976) chez Anoptichtys et Astyanax, constatent une augmentation des structures irrégulières au cours de la vie des individus éfudiés (remarquons que les Brochets utilisés éłaient relativement jeunes); (2) Omura (1975) remarque qu'une exposition continue à la lumière accélère le processus de dégénérescence chez les populations cavernicoles d'Astyanax. Chez ces mêmes populations, exposées à un rythme photopériodique naturel, le processus de dégénérescence est ralenti (Herwig, 1976). Ceci permet à Herwig de conclure : « Light may influence but not prevent this process. It is therefore postulated that the regression of the pineal outer segments in cave specimens of Astyanax mexicanus is genetically determined. The expression of the regressive traits depends on the environmental light conditions ». II est intéressant de noter que chez Esox, la région moyenne - seule à présenter une accumulation importante de segments externes en dégénérescence - est la plus exposée à la lumière car non recouverte de méninges pigmentées (Falcon, 1979). En relation avec ce processus, on observe parallèlement, dans la lumière de cette région, de nombreuses cellules phagocytantes ainsi qu'une accumulation de structures membranaires isolées, plus ou moins désorganisées (Falcon, 1979).

L'ensemble de ces données nous conduit à penser que les segments externes irréguliers de l'organe pinéal d'Esox correspondent à un stade intermédiaire de rudimentation. Ils se situent entre ceux des $P$ et ceux à structures en massue (dépourvus de disques) des PR des Sauropsidés (réf. in Collin, 1971, 1979 ; voir également le paragraphe 3 de la discussion). Chez les Reptiles ef les Oiseaux, les segments externes réguliers sont rares ou absents, les formes irrégulières assez nombreuses et les expansions en massue, dépourvues de disques, nombreuses. Chez Esox, les segments externes réguliers et irréguliers sont bien représentés, alors que les expansions bulbeuses sont très rares. Ainsi, nous considérons que le processus de dégénérescence, responsable de la rudimentation graduelle des segments externes, est génétiquement déterminé. Il est en place chez les Poissons (ef s'amorce de façon vraisemblable, chez les Cyclostomes : Collin, 1969 et communication personnelle) et s'accentue au cours de l'évolution des Vertébrés, conduisant à la disparition complète des structures ciliaires chez certains Mammifères (réf. in Collin, 1979).

b) Régression du pédicule basal. - Pour établir l'existence de CTP à caractères rudimentaires dans l'organe pinéal d'Esox, «la régression du pôle récepteur doit s'accorder avec celle du pôle neurotransmetfeur. C'est la raison pour laquelle il est nécessaire, malgré les grandes difficultés dues aux intrications cellulaires, de relier l'observation du segment externe à celle des autres régions de la cellule ") (Collin, 1969).

En l'absence d'observation de RS dans les pédicules de CTP de la région moyenne, une régression des pôles transmetteurs parallèle à celle des pôles transducteurs est suggérée. Les RS décrits par Owman et Rüdeberg (1970) chez Esox, correspondent en réalité à des RCV. Ceux-ci, à l'inverse des RS, peuvent difficilement être considérés 
comme impliqués dans la neurotransmission. D'après Collin (1969), il s'agit soit de formations rudimentaires (structures reliques), soit d'organites ayant subit une mulation de fonction. Des recherches expérimentales nombreuses et récentes n'ont pas encore permis d'établir leur rôle dans les pinéalocytes de Mammifères (réf. in Collin, 1979). Certains auteurs (réf. in Owman et Rüdeberg, 1970) ont rapporté l'existence de «tight junctions » et suggèrent qu'elles pourraient être des synapses électrotoniques. Mais seules les « gap junctions » assurent cette fonction (Staehelin, 1974). Les méthodes classiques de microscopie électronique ne permettant pas de différencier ces 2 types de jonctions, nous ne pouvons pas, sans données complémentaires, justifier une telle hypothèse.

Cerfains pédicules de CTP de la région moyenne viennent prendre appui sur la lamelle basale, éfablissant ainsi une polarité vasculaire. II est probable (en fonction des données acquises : réf. in Collin, 1971, 1979) qu'ils appartiennent à des CTP à caractères rudimentaires (seuls les pédicules de photorécepteurs rudimentaires, PR, atteignent la lamelle basale chez les Sauropsidés). Ces prolongements asynaptiques appartiennent-ils à un type particulier de CTP à rudimentation plus poussée (par exemple à celui dont le segment externe ne présente qu'une expansion bulbeuse) ? Nous ne pouvons, à l'heure actuelle, répondre à cette question (rappelons que les vésicules claires sont peu nombreuses et que des RCV n'ont pu être observés).

En résumé, cette étude permet de dégager, pour les Anamniotes, les faits originaux suivants :

- rudimentation bipolaire d'un certain nombre de CTP ;

- ce phénomène affecte plus particulièrement la région moyenne (voir également Falcon et Mocquard, 1979).

3. Comparaison entre les CTP à caractères rudimentaires du Brochet ef les PR des Sauropsidés.

Si certaines CTP de l'organe pinéal du Brochet possèdent à des degrés variés des caractères de rudimentation, elles diffèrent des PR des Sauropsidés pour les raisons suivantes:

(a) la rudimentation du pôle transducteur n'est pas aussi marquée; les formes intermédiaires entre segments externes de $P$ et de PR sont nombreuses (voir paragraphe précédent);

(b) les seules données ultrastructurales ne permettent pas de définir, sans équivoque, une activité sécrétoire de type neurohormonal :

- Si des contacts synaptiques ne sont plus établis avec les dendrites des NS, les pédicules n'entrent encore que rarement en contact avec la lamelle basale. Dans ce cas, les électronographies suggèrent une activité neuroendocrine, surtout dans la région moyenne. D'ailleurs, l'ultrastructure de l'endothélium des capillaires de la même région semble plus particulièrement adaptée aux échanges avec l'épithélium épiphysaire (Falcon, 1979).

- Définir une activité sécrétoire implique, entre autres conditions, la mise en évidence d'organites spécifiques, spécialisés dans le stockage des principes actifs de type neurohormonal, comme les « vésicules à cœur dense » des PR et Pi des Sauropsidés. 
Les « vésicules à cœur dense » du Brochet, comparables par leur structure à celles décrites chez les Cyclostomes (Collin, 1969) et certains Poissons (Scyliorhinus: Rüdeberg, 1969 ; Latimeria : Hafeez et Merhige, 1977), sont très rares. Leur contenu ne peut être actuellement assimilé aux sécrétions protéiques et indoliques intragranulaires des $P R$ et $\mathrm{Pi}$ des Amniotes (réf. in Collin, 1979). De plus, ces vésicules sont observées dans les $\mathrm{P}$ comme dans les CTP à caractères rudimentaires ; Collin (1979) conclut : "The exact nature and physiological significance of the vesicle population of the $P$ cells are purely hypothetical $)$.

Le contenu floconneux des rares inclusions observées entre les conduits du réticulum, pourrait traduire une activité de synthèse et/ou de stockage d'une substance de nałure inconnue (protéique ou glycoprotéique ?).

Les vésicules claires ( 350 à $500 \AA$ ) ne peuvent être considérées comme des vésicules synaptiques dans les pédicules de CTP à caractères rudimentaires, dépourvus de différenciations synaptiques. L'hypothèse qu'elles pourraient éventuellement contenir un principe actif différent des neurotransmetteurs doit être également soumise à l'épreuve expérimentale.

\section{Glycogène ef glycoprotéines.}

La technique de Thiéry a permis de mettre clairement en évidence une accumulation importante de particules $\alpha$ et $\beta$ de glycogène dans les CTP de l'organe pinéal d'Esox. Le glycogène constitue un véritable marqueur de ce type cellulaire et confirme la mise en évidence des contacts des pédicules de CTP à caractères rudimentaires avec la lamelle basale.

Si des tests ultracyłochimiques n'ont jamais été effectués chez les Vertébrés inférieurs, les études ultrastructurales ont permis de constater la présence de particules en quantité variable, assimilées à du glycogène, dans les CTP de la plupart des Téléostéens éfudiés (réf. in Falcon, 1979). Chez Thunnus cependant (Murphy, 1971), le glycogène est observé dans les cellules interstitielles de type épendymaire. Aucun auteur ne signale la présence de paraboloïde chez les Téléostéens, comme dans les P ef PR des Reptiles ou les cônes rétiniens (réf. in Collin, 1979).

Le glycogène constitue une forme d'énergie rapidement mobilisable, utilisée dans les divers métabolismes cellulaires. De façon vraisemblable, il intervient dans la photoréception et la neurotransmission des cellules $P$.

Il est difficile de préciser à quel type cellulaire appartiennent les structures présentant des mucopolysaccharides. S'agit-il des organites observés dans les cellules à inclusions indéterminées (Falcon, 1979) ? En effet : (a) ces structures ne sont observées qu'exceptionnellement; $(b)$ elles rappellent par leur forme et dimensions les inclusions précitées ; (c) des structures de taille ef forme identique ne sont jamais rencontrées dans les cellules interstitielles ou les neurones sensoriels en microscopie électronique (Falcon, 1979 ; Falcon et Mocquard, 1979).

Selon Rambourg (1969), le PTA permet la mise en évidence des groupements hydroxyles des glycoprotéines à $\mathrm{pH}$ très acide. Mais la spécificité de la méthode est très largement discutée (réf. in Juillard et Collin, 1978). Le PTA révélerait également tous les groupements électro-positifs, tels que les radicaux ammoniacaux des protéines (réf. in Perrin-Waldemer, 1977). De cette manière pourrait s'expliquer le marquage 
des fibres de collagène (à structure protéique) dans l'espace périvasculaire. La méthode de Rambourg a permis, comme dans la majorité des cas (Rambourg, 1969), de colorer la lamelle basale et les espaces intercellulaires. Mais le marquage est difficile à interpréter : glycoprotéines du «cell-coat » ou protéines membranaires ? Aucune structure glycoprotéique n'a été mise en évidence par la méthode de Thiéry, dont la spécificité est difficile à mettre en cause. En effet, des coupes témoins réalisées dans le duodénum de Souris et traitées parallèlement à celles de l'organe pinéal, présentaient une forte réaction au niveau du «cell-coat ». Pour les mêmes raisons, exposées précédemment, nous ne pouvons interpréter définitivement le marquage observé dans les membranes des vésicules claires de 350 à $500 \AA$. Les inclusions à contenu coloré par le PTA (fig. 40) sont très probablement localisées dans les cellules interstitielles car leur forme, dimensions, disposition, rappellent les citernes ergastoplasmiques observées dans ce type cellulaire. Comme nous l'avions précédemment suggéré (Falcon, 1979), le matériel coloré est peut-être de nature protéique. Compte tenu de l'importance de la coloration, des glycoprotéines auraient très probablement été détectées par la méthode de Thiéry. En bref, il sera nécessaire de préciser ultérieurement par d'autres techniques la nature protéique et/ou glycoprotéique de certaines structures.

\section{Conclusions.}

Les résultats apportés par cette étude nous permettent de tirer les conclusions suivantes :

(1) L'existence de photorécepteurs de type cône et de connexions synaptiques de type ruban (à la jonction entre pédicule de CTP ef dendrites des neurones sensoriels pinéalofuges) dans l'épithélium distal et surtout proximal est hautement en faveur d'une activité photosensorielle dans ces 2 régions.

(2) La rudimentation de certaines cellules sensorielles (de façon vraisemblable, génétiquement contrôlée) est déjà mise en place chez les Anamniotes, conformément à l'hypothèse proposée par Collin (1969). Les CTP à caractères rudimentaires, plus particulièrement localisées dans la région moyenne, établissent la transition entre les $P$ typiques des Vertébrés inférieurs et les PR, à segment externe en massue, des Sauropsidés. Elles peuvent être considérées comme PR dans la mesure où elle ne sont plus aptes à capter l'information d'origine lumineuse (rudimentation plus ou moins accentuée du pôle transducteur) et à transmettre le message correspondant aux neurones sensoriels pinéalofuges (rudimentation du pôle neurotransmetteur). Toutefois, contrairement aux PR des Sauropsidés, les critères d'une activité sécrétoire de type neurohormonal ne peuvent être clairement établis d'après les seules données ultrastructurales. Nos résultats élargissent aux Vertébrés le concept de pluralité des CTP (proposé par Collin, chez les Amniotes : voir introduction).

(3) La distribution des 2 catégories de CTP (riches en glycogène) est hétérogène dans l'épithélium épiphysaire ; elle se superpose parfaitement à la "zonation" morphologique de ce dernier et renforce l'hypothèse d'une «zonation » fonctionnelle, émise précédemment (Falcon, 1979). 
Pour vérifier et préciser ces résultats, nous envisageons actuellement une étude électrophysiologique (coll. Pr. E. Dodt), dans les différentes régions où apparaissent déjà des potentialités photoréceptrices variées. La rudimentation d'une partie des CTP laisse supposer une régression partielle quantitative et/ou qualitative des neurones sensoriels pinéalofuges, qu'il est nécessaire d'envisager mainfenant.

Reçu en novembre 1978

Accepté en décembre 1978.

Remerciements. - Je remercie M. le Prof. J. P. Collin et Mlle Juillard pour les nombreux conseils ef le soutien qu'ils m'ont apportés. Ce travail a pu être réalisé grâce à une bourse et à un contrat DGRST (no 76.7.0043) et à l'appui financier du CNRS. Je remercie Mlle $D$. Decourt qui a assuré la dactylographie de ce mémoire.

\section{Références}

CLABOUGH J., 1973. Cytological aspects of pineal development in rats and hamsters. Am. J. Anat., $137,215-230$.

COLLIN J. P., 1969. Contribution à l'étude de l'organe pinéal. De l'épiphyse sensorielle à la glande pinéale : modalités de transformation et implications fonctionnelles. Ann. Stat. Biol. Besse-enChandesse, Suppl. 1, 1-357.

COLLIN J. P., 1971. Differentiation and regression of the cells of the sensory line in the epiphysis cerebri, 79-125. In WOLSTENHOLME G. E. W., KNIGHT J., The pineal gland, Churchill Livingstone, Edinburg-London.

COLLIN J. P., 1977. La rudimentation des photorécepteurs dans l'organe pinéal des Vertébrés, 393-407. In RAYNAUD A., Mécanismes de la rudimentation des organes chez les embryons de Vertébrés. Coll. int. CNRS no 266, Paris.

COLLIN J. P., 1979. The pineal organ of vertebrates. Ultrastructure, cytochemistry and functional evolution of the chief cells. Int. Rev. Cytol. (in press).

COLLIN J. P., JUILLARD M. T., FALCON J., 1977. Localization of 5-hydroxytryptamine and protein(s) in the secretion granules of the rudimentary photoreceptor cells in the pineal of Lacerta. J. Neurocytology, 6, 541-554.

FALCON J., 1979. L'organe pinéal du Brochet (Esox lucius, L.). I. - Etude anatomique et cytologique. Ann. Biol. anim. Bioch. Biophys., 19, 445-465.

FALCON J., MOCQUARD J. P., 1979. L'organe pinéal du Brochet (Esox lucius, L.). III. - Voies intrapinéales de conduction des messages photosensoriels. Ann. Biol. anim. Bioch. Biophys. (in press).

HAFEEZ M. A., FORD P., 1967. Histology and histochemistry of the pineal organ in the sockeye salmon, Oncorhyncus nerka, Walbaum. Can. J. Zool., 45, 117-126.

HAFEEZ M. A., MERHIGE M. E., 1977. Light and electron microscopic study on the pineal complex of the coelacanth Lafimeria chalumnae, Smith. Cell Tiss. Res., 178, 249-265.

HERWIG H. J., 1976. Comparative ultrastructural investigations of the pineal organ of the blind cave fish, Anoptichthys jordani and its ancestor the eyed river fish, Astyanax mexicanus. Cell Tiss. Res., 167, 297-324.

JUILLARD M. T., COLLIN J. P., 1978. The avian pineal organ : evidence for a proteinaceous component in the secretion granules of the rudimentary photoreceptor cells. An ulfracytochemical and pharmacological study in the parakeet. Biol. Cell., 31, 51-58.

JUILLARD M. T., HARTWIG H. G., COLLIN J. P., 1977. The avian pineal organ. Distribution of endogenous monoamines; a fluorescence microscopic, microspectrofluorimetric and pharmacological study in the parakeet. J. Neural. Transm., 40, 269-287. 
MEINIEL A., 1976. Contribution à l'étude du complexe pariétal embryonnaire des Lacertiliens. Différenciation cellulaire de l'épiphyse de Lacerta vivipara (Jacquin) en rapport avec les activités sensorielle, sécrétoire et neurohumorale (biosynthèses indoliques). Thèse, Univ. Clermont-Ferrand II, 223 pp.

MURPHY R. C. 1971. The structure of the pineal organ of the bluefin tuna, Thunnus thynnus. J. Morph., 133, 1-16.

OKSCHE A., KIRSCHSTEIN H., 1967. Die Ultrastruktur der Sinneszellen im Pinealorgan von Phoxinus laevis L. Z. Zellforsch., 78, 151-166.

OMURA Y., 1975. Influence of light and darkness on the ultrastructure of the pineal organ of the blind cave fish, Astyanax mexicanus. Cell Tiss. Res., 160, 99-112.

OMURA Y., OGURI M., 1971. The development and degeneration of the photoreceptor outer segment of the fish pineal organ. Bull. jap. Soc. Sci. Fish., 37, 851-860.

OWMAN C., RÜDEBERG C., 1970. Light, fluorescence, and electron microscopic studies on the pineal organ of the pike Esox lucius, L., with special regard to 5-hydroxytryptamine. $Z$. Zellforsch., 107, 522-550.

PERRIN-WALDEMER C., 1977. Détection de glycoprotéines et de protéines par l'acide phosphotungstique au niveau des glandes accessoires mâles de Drosophila melanogoster incluses au GMA. Biol. Cell., 30, 171-176.

RAMBOURG A., 1967. Détection des glycoprotéines en microscopie électronique : coloration de la surface cellulaire et de l'appareil de Golgi par un mélange acide chromique-phosphotungstique. C. R. Acod. Sci., Poris, Sér. D, 265, 1426-1428.

RAMBOURG A., 1969. Localisation ultrastructurale ef nature du matériel coloré au niveau de la surface cellulaire par le mélange chromique-phosphotungstique. J. Microscopie, 8, 325-342.

RAMBOURG A., HERNANDEZ W., LEBLOND C. P., 1969. Detection of complex carbohydrates in the Golgi apparatus of rat cells. J. Cell Biol., 40, 395-414.

RÜDEBERG C., 1968. Structure of the pineal organ of the sardine, Sardina pilchardus sardina (Risso), and some further remarks on the pineal organ of Mugil spp. Z. Zellforsch., 84, 219-237.

RÜDEBERG C., 1969. Light and electron microscopic studies on the pineal organ of the dogfish, Scyliorhinus conicula L. Z. Zellforsch., 96, 548-581.

RÜDEBERG C., 1970. Light and electron microscopic investigations on the pineal and parapineal organs of fishes. Thesis, Lund, $29 \mathrm{pp}$.

STAEHELIN L. A., 1974. Structure and function of intercellular junctions. Int. Rev. Cyfol., 39, 191-283.

TAKAHASHI H., 1969. Light and electron microscopic studies on the pineal organ of the goldfish, Carassius auratus L. Bull. Fac. Fish., Hokkaido Univ., 20, 143-157.

TAKAHASHI H., KASUGA S., 1971. Fine structure of the pineal organ of the medaka Oryzias latipes. Bull. Fac. Fish., Hokkaido Univ., 22, 1-10.

THIÉRY J. P., 1967. Mise en évidence des polysaccharides sur coupes fines en microscopie électronique. J. Microscopie, 6, 987-1018.

YOUNG R.W., 1977 . The daily rhythm of shedding and degradation of cone outer segment membranes in the lizard retina. J. ultrastruct. Res., 61, 172-185.

ZIMMERMAN B. L., TSO M. O. M., 1975. Morphologic evidence of photoreceptor differentiation of pinealocytes in the neonatal rat. J. Cell Biol., 66, 60-75. 